\title{
Effect of GSR Biofeedback Relaxation Training on Blood Glucose and Anxiety Level of Type 2 Diabetic Patients
}

\author{
Mahendra Kumar ${ }^{1}$, Dr. Deepak Pandey ${ }^{2}$, Dr. Priyamvada Shrivastva ${ }^{3} *$
}

\section{ABSTRACT}

The objective of this study was to determine the effect of GSR (galvanic skin resistance) biofeedback relaxation technique on blood glucose and anxiety level of type 2 diabetes patients. The total sample size for this study was 12 diabetes patients include 6 male and 6 female participants. Incidental sampling method was adopted to select the sample. Intervention program for the study was 20 days for each patient. The blood glucose and anxiety level were measured before and after the training on day 1st and 20th. Result indicates that there is significant mean difference between the score of blood glucose in pre and post conditions of the interventions. The blood sugar level of type 2 diabetes patients is lowered in post condition indicating the influence of biofeedback intervention. A sample of adequate size may reveal a significant effect of biofeedback. There is significant mean difference between the score of state - trait anxiety among pre and post test score of type 2 diabetes patients.

Keywords: GSR Biofeedback Relaxation Training, Blood Glucose, Anxiety, Type 2 Diabetic Patients

Stress and anxiety have become part and parcel of every ones day to day life. Stress and sedentary life style often lead to chronic health conditions like diabetes and other non communicable problems. Stress an Important factor in Type 2 diabetes (Surwit, 2002). Some evidence suggests that chronic stress, negative emotions, and other Psychosocial factor increase risk for developing diabetes. Stress is a major factor of circulatory system. And stress plays an important role in susceptibility, progress, and outcome of cardiovascular diseases. Esch et al. (2002). Carrillo and Vázquez (1994) psychological stress can affect the control of diabetes: directly and indirectly this study suggests that relaxation or social skills training, to help diabetic patients learn to manage with stress. McGrady and Horner (1999) suggested that mood has an important impact on the response to biofeedback assisted relaxation.

\footnotetext{
${ }^{1}$ Research Scholar, School of Psychology, Pt. Ravishankar Shukla University, Raipur, India

${ }^{2}$ Research Associate, School of Psychology, Pt. Ravishankar Shukla University, Raipur, India

${ }^{3}$ Professor \& Head, School of Psychology, Pt. Ravishankar Shukla University, Raipur, India

*Responding Author

(C) 2016 Kumar M, Pandey D, Shrivastva P; licensee IJIP. This is an Open Access Research distributed under the terms of the Creative Commons Attribution License (http://creativecommons.org/licenses/by/2.0), which permits unrestricted use, distribution, and reproduction in any Medium, provided the original work is properly cited.
} 


\section{Effect of GSR Biofeedback Relaxation Training on Blood Glucose and Anxiety Level of Type 2 Diabetic Patients}

Diabetes is one of the most important chronic diseases; it is the risk factors for chronic kidney disease (Kashinath et. al., 2014), because with a high and incidence rate in the world. This disease and its complications contain that major burden of disease proportion in the world. Diabetes is not a single disease - There are mainly three main types of diabetes:

\section{Type 1 diabetes, Type 2 diabetes, and Gestational diabetes mellitus (GDM).}

The international diabetes federation (IDF, 2011) estimates that in worldwide there are 366 million people living with diabetes in 2011 internationally and this is expected to be 552 million by 2030 ( $54 \%$ increase). In India higher number of people living with diabetes compare to other country, the total involving 50.8 million people with diabetes in the age group of 20 to 79 in 2010 and this number is approximate to reach 87.0 million people by 2030 (IDF, 2009). IDF (2011) estimates that India alone has 61.3 million people living with diabetes with the increase of diabetes problem in adults. The prevalence of mood and anxiety disorders is higher in individuals with type 2 diabetes compared with the general population. The effective intervention patterns were reserved. The evidence revealed from the review of literature indicates that psychological interventions contribute in better management of life style diseases. Kashinath et al. (2014) noted that yoga is effective intervention for decrease of blood pressure, heart rate and fatigue, pain associated with CKD, it is work on physical and psychological level. Schwartz (1995), Biofeedback assisted relaxation has been found to be useful in stress-related disorders. Palekar et al. (2015) studied galvanic skin resistance-aided biofeedback training is successful technique for reduction of the pulse rate, respiratory rate, BP, and perceived stress in physiotherapy students. Ghazavi et. al. (2008) revealed massage therapy and progressive muscle relaxation techniques are effective to decrease blood glucose level in diabetic children. Agnihotri, Paul and Sandhu, (2007) Noted that Electroencephalography, and Electromyography, Biofeedback trainings are useful in the treatment of Generalized Anxiety Disorder. Zaichowsky et al. (1986) found children training in biofeedback assisted relaxation demonstrated significant control over their heart and respiration rates and skin temperature. Bembalgi et al. (2013) found that electromyography biofeedback more valuable technique compare to galvanic skin resistance. Khanna, Paul and Sandhu (2007) studied GSR biofeedback and PMR training were able in reduction of anxiety score and pulse rate. With increasing prevalence rate of diabetes type 2, apart from drug therapy to psychological intervention is important. In view of earlier studies an attempt is made to see the impact of psychological intervention on management of type 2 diabetes thus the objectives and hypothesis of following:

\section{Objectives}

1. To see the effectiveness of (GSR) biofeedback relaxation technique on blood glucose level of the type 2 diabetes patient.

2. To see the effectiveness of (GSR) biofeedback relaxation technique on anxiety level of the type 2 diabetes patient. 


\section{Effect of GSR Biofeedback Relaxation Training on Blood Glucose and Anxiety Level of Type 2 Diabetic Patients}

\section{Hypotheses}

1. There will be difference in the post condition on blood glucose level of type 2 diabetic patients.

2. There will be difference in the post condition on anxiety score of type 2 diabetic patients.

\section{METHOD}

\section{Sample}

The sample of the study consists of 12 patients (6 male \& 6 female) suffering from diabetes type 2 and enrolled in the clinics of Raipur C. G. In the present study incidental sampling method was adopted to select the sample. The research design adopted for this study was pre test - post test experimental design. The psychological intervention programme was given to all participants. Biofeedback (GSR) relaxation training was given to 12 patient out of 12, 10 patients could complete and 2 participant dropout.

\section{Tools}

1. Anxiety- The anxiety is measured by using the state trait anxiety inventory (STAI) developed by Dr. Roma Pal and Dr. Govind Tiwari (1985).

2. Blood glucose test by pathological lab taken as secondary data.

3. GSR biofeedback relaxation technique was use as experimenter variable.

\section{Procedure}

The study was approved by Ethical Committee of Pt. RSU Raipur C.G. prior to the start of data collection. All the diabetes Participants of the relaxation training group were explained about the relaxation training and previous research supporting the effectiveness of biofeedback training in relaxation. A verbally consent was taken from each of the subjects prior to the training. all 12 diabetes patient were assessed prior to intervention on blood glucose and anxiety level than the biofeedback relaxation training was provided for 30 min for 20 consecutive days in neat, clean and quiet room without any external noise or glaring light at the home for each participants.

In the GSR biofeedback training group before the commencement of training, the subject was made to sit comfortably on a chair, placed in front of GSR machine (GSR Biofeedback) the electrodes were fixed on the index and ring finger using and the subject was instructed to relax voluntarily using visual feedback from the machine.

\section{RESULT \& DISCUSSION}

The first objective of this study was to determine the effect of GSR (galvanic skin resistance) biofeedback relaxation technique on blood glucose level of type 2 diabetes patient. Data obtained was statistical analyzed using paired sample ' $t$ ' test method was used with help of SPSS $\left(16^{\text {th }}\right)$ version. 
Effect of GSR Biofeedback Relaxation Training on Blood Glucose and Anxiety Level of Type 2 Diabetic Patients

Table 1:- Mean, S.D. and t-value of Pre-blood sugar level and Post-blood sugar level of type 2 diabetes patients.

\begin{tabular}{|l|l|l|l|l|l|}
\hline GROUPS & N & MEAN & S. D. & t-value & Sig. level \\
\hline $\begin{array}{l}\text { Pre blood } \\
\text { sugar level }\end{array}$ & \multirow{2}{*}{10} & 171.7 & 48.44 & & \\
\cline { 1 - 1 } $\begin{array}{l}\text { Post blood } \\
\text { sugar level }\end{array}$ & & 151.42 & 55.54 & 2.179 & $\mathrm{P}<.05$ \\
\hline
\end{tabular}

It is observed from the table showing that ' $t$ ' value is significant at 0.05 level thus it can be said that there is difference in pre and post condition of Blood sugar level of the patient. The mean value obtained in pre \& post condition shows that is post condition blood sugar level is lowered.

Table 2: Mean, S. D. and t-value of Pre-test score and Post-test score of type 2 diabetes Participant on state and trait anxiety levels.

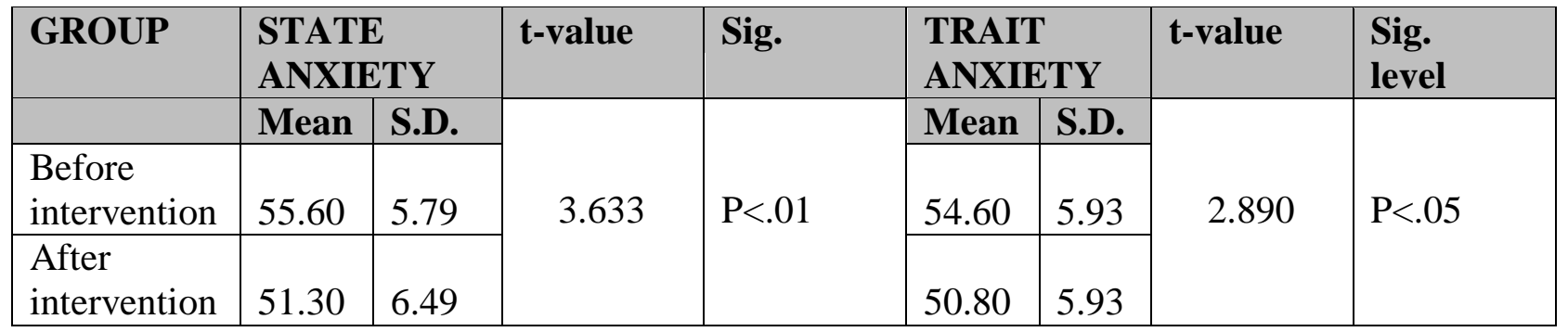

In table no. 2, the t-value for state anxiety of, before intervention and after intervention type 2 diabetes patient is 3.633 significant at 0.01 level and the t-value for trait anxiety of before and after intervention of type 2 diabetes patient is 2.890 significant at 0.05 level.S0, both values are significant at 0.01 and 0.05 level and hypothesis (2) are also accepted. It shows that there is significant mean difference between the score of state anxiety among pre test (Before intervention) and post test (After intervention) of type 2 diabetes patient. And also there is significant mean difference between the score of trait anxiety among pre test (Before intervention) and post test (After intervention) of type 2 diabetes patient.

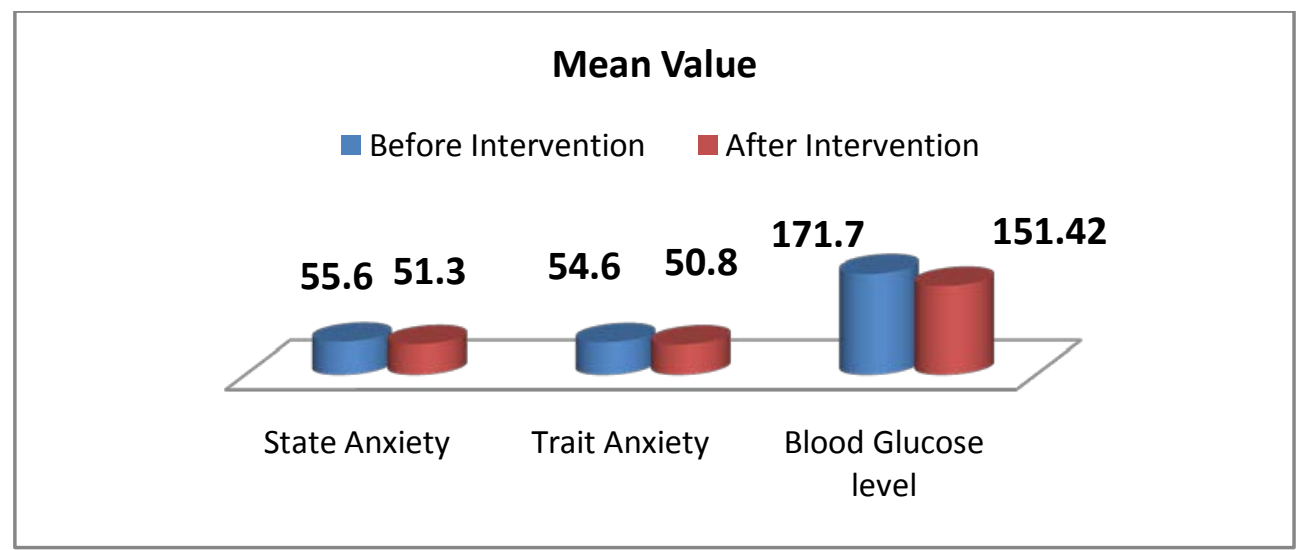

Figure 1: Graphical representation of mean value on before intervention and after intervention.

(C) The International Journal of Indian Psychology, ISSN 2348-5396 (e) | ISSN: 2349-3429 (p) | 199 


\section{Effect of GSR Biofeedback Relaxation Training on Blood Glucose and Anxiety Level of Type 2 Diabetic Patients}

The result of the study reveal that biofeedback (GSR) is effective in reducing the blood glucose level and anxiety level (at state and trait condition) It means that biofeedback GSR is effective technique for reducing the blood glucose level and the anxiety level of the individual (state \& trait both).the present study supports the findings of earlier researches revealing the effectiveness of GSR biofeedback in reducing the problem of life style disease. Khanna et al. (2007) noted that GSR (galvanic skin resistance ) biofeedback and PMR (progressive muscular relaxation ) training were able to reduce the high pulse rates and anxiety but PMR training was found to be more effective than GSR biofeedback training in reducing the pulse rate and anxiety score. Bembalgi and Naik (2013) found Electromyography and galvanic skin resistance biofeedback are helpful technique for the treatment of Tension type headache. Mcginnis et al (2005) noted that this study supports the use of biofeedback and relaxation in mood of type 2 patients. Biofeedback and relaxation are effective for depression and anxiety (Nagai, Goldstein, Fenwick, and Trimble, 2003). Datey (1980) found GSR-bf has been used in the treatment of stress, hypertension, epilepsy, etc. Agnihotri et al. (2007) investigated the effect of electromyographic (EMG) and electroencephalographic (EEG) BF relaxation trainings on generalized anxiety disorders. They reported that both EMG and EEG BF relaxation trainings are effective in state and trait anxiety after 12 days of treatment, thus the present study supports importance of Psychological intervention in life style disease and diabetes type -2 .

\section{CONCLUSIONS}

It is concluded that the findings of the result clearly indicated that GSR (galvanic skin resistance) biofeedback relaxation are very useful and effective technique for controlling anxiety level and glucose level of the type -2 diabetic patients.

\section{Acknowledgments}

The author appreciates all those who participated in the study and helped to facilitate the research process.

\section{Conflict of Interests}

The author declared no conflict of interests.

\section{REFERENCES}

Agnihotri H, Paul M, Sandhu JS, Biofeedback Approach in the Treatment of Generalized Anxiety Disorder. Iran J Psychiatry, 2007; 2:90-5.

Bembalgi V, Naik KR, Comparative study on the efficacy of electromyography and galvanic skin resistance biofeedback in tension type headache: a single blinded randomized controlled trial. Int J Disabil Hum Dev, 2012; 12 (3): 353-361.

Carrillo FXM, Vázquez MB, Emotional variables on diabetes control: intervention strategies. anales de psicología, 1994; 10(2), 189-198. 
Effect of GSR Biofeedback Relaxation Training on Blood Glucose and Anxiety Level of Type 2 Diabetic Patients

Datey KK, Role of biofeedback training in hypertension and stress. J Postgrad Med, 1980; 26:68 $-73$.

Esch T, Stefano GB, Fricchione GL, Benson H, Stress in cardiovascular diseases, 2002.

Ghazavi Z, Talakoob S, Abdeyazdan Z, Attari A, Joazi M, Effects of massage Therapy and muscle relaxation on glycosylated haemoglobin in children. Shiraz E - Medical Journal, Vol. 9, No. 1, January 2008.

Kashinath GM, Hemant B, Praerna C, Nagarathna R, Nagendra HR, Role of Yoga in Chronic Kidney Disease: A Hypothetical Review. J Nephrol Ther,2014 1(4), 167.

Khanna A, Paul M, Sandhu JS, Efficacy of two relaxation techniques in reducing pulse rate among highly stressed females. Calicut Medical Journal, 2007;5:e2.

Mcginnis RA, Mcgrady A, Cox, Stephen A, Dowling, Kimber A, Biofeedback-assisted relaxation in type 2 diabetes. Diabetes care, 2005;.28, 2145-2149

McGrady A,and Horner J, 1999. Role of Mood in Outcome of Biofeedback Assisted Relaxation Therapy in Insulin Dependent Diabetes Mellitus. Applied psychophysiology and Biofeedback, Vol. 24, No. 1,

Med Sci Monit, 2002; 8(5): 93-101.

Nagai Y, Goldstein LH, Fenwick PB, Trimble MR, Clinical efficacy of galvanic skin response biofeedback training in reducing seizures in adult epilepsy: a preliminary randomized controlled study. Epilepsy Behav, 2004; 5(2):216 - 23.

Palekar TJ, Mokashi MG, Anwer S, Kakrani AL, Alghadir AH, Effect of Galvanic Skin Resistance Aided Biofeedback Training in Reducing Pulse Rate, Respiratory Rate and Blood Pressure Due to Perceived Stress in Physiotherapy Students. Turk J Phys Med Rehab,2016; 61:116-9.

Sarafino EP, Smith PW, HELTH PSYCHOLOGY biopsychosocial interactions. the college of new jersey,U.K; 2011.

Schwartz MS, Biofeedback: A Practitioners Guide (2nd ed.). New York: Guilford Press, 1995.

Surwit R, Type 2 Diabetes and stress. Diabetes voice,2002; 47, 4.

Zaichkowsky LB, Zaichkowsky LD, Yeager, John, Biofeedback-assisted relaxation training in the elementary classroom Elementary School. Guidance \& Counselling, 1986; 20, (4), 261-267.

How to cite this article: Kumar M, Pandey D, Shrivastva P (2016), Effect of GSR Biofeedback Relaxation Training on Blood Glucose and Anxiety Level of Type 2 Diabetic Patients, International Journal of Indian Psychology, Volume 4, Issue 1, No. 82, ISSN:2348-5396 (e), ISSN:2349-3429 (p), DIP:18.01.160/20160401, ISBN:978-1-365-59365-9

(c) The International Journal of Indian Psychology, ISSN 2348-5396 (e)| ISSN: 2349-3429 (p) | 201 